C.C.I.F. and the International Electrotechnical Commission (I.E.C.) :

(1) That the international standard of concert pitch shall be based on a frequency of 440 cycles per second for the note A in the treble clef. ("La normale".)

(2) That this value shall be maintained within the closest limits possible, by soloists, orchestras, choirs, etc., throughout all musical performances, and also in recorded music.

(3) That with a view to reducing the necessary tolerances to acceptable values, a set of technical recommendations be drawn up, preferably on the basis of international co-operation.

An appendix to the recommendations relates to a future programme of study designed for early discussion, so as to render effective as soon as possible the practical observance of the new standard concert pitch: for example, the differential influence of temperature on the various orchestral instruments and the consequential tuning adjustments before and during a performance; the feasibility of transmitting the standard pitch by means of broadcasting or telephone; the provision of sub-standards of pitch, portable or otherwise, and the advisability of their verification by an official laboratory; the production of specifications dealing with the appropriate tolerances in the manufacture of musical instruments; and the setting up of supervisory safeguards, both national and international, for verifying the observ. ance of the new standard pitch and so preventing the possibility of its falling into desuetude, as has occurred with the Vienna standard.

The success of the Conference was a happy vindication of the decision to go forward with the plans for bringing the delegates of the different countries together, despite the troubled nature of the times. The delegates further consorted in complete and amicable accord on the occasions of visits to the Acoustical Laboratory of the National Physical Laboratory by the kind invitation of the Director, and to Lyne, Capel, Surrey, at the invitation of Captain Broadwood, whose beautiful house and estate, in all the glory of the spring foliage, formed a lovely setting for his genial hospitality and the delightful unaccompanied old English melodies of the famous Tudor Singers under the direction of Mr. Cuthbert Bates.

\title{
Telephony in the United States
}

\section{$\mathrm{T}$} HE annual report by the directors of the American Telephone and Telegraph Co. for the year 1938 is of great interest. The taxes last year were equal to about 80 cents per month per telephone, which is about 14 per cent of the average telephone bill, or about one third of the total pay roll. Notwithstanding the heavy taxation and increased wages, the earned dividends for the last two years were nearly the same.

Until 1927, the longest distance a telephone call could be made was about 3,000 miles; to-day there is no limit. We can talk round the world. The improvement in transmission on a call from New York to San Francisco as compared with twenty years ago when trans-continental service was inaugurated is roughly equivalent to the difference between conversing in an open field at a distance of several hundred feet and conversing with someone in the same room at about one third the cost. Five years ago the time of making a long-distance connexion was reduced from $7 \cdot 5$ minutes to 3 minutes. Last year a direct radio telephone circuit from San Francisco to Australia was made, replacing the original route from New York via London. This new circuit is several thousand miles shorter and made possible a substantial reduction in the price of a call.

The ocean liner Nieuw Amsterdam has been added to those with which the Bell system operates shipto-shore radio telephone service. Twelve shore stations of the Bell system and its connecting companies now serve nearly a thousand small vessels on the Atlantic and Pacific coasts and on the Great Lakes.

The damage experienced by the destructive effects of fires, floods, tidal waves and hurricanes in 1938 was the most extensive ever experienced. In September all these destructive forces combined, causing a disaster in the eight north-eastern States affecting the greatest number of telephones and communities since the telephone was invented. More than half a million telephones were silenced, and 240 communities were isolated. The wreckage of telephone plant put the Bell system to the greatest test it had ever been called on to face-a test of the organization, of its men and women, and of its resources of equipment and supplies. More than 2,300 trained men with 615 motor-vehicles were loaned by fourteen telephone companies. Enormous quantities of materials were rushed in promptly by the Western Electric Co. The Bell companies in the stricken area, assisted by the resources of the entire Bell system, successfully met the challenge of the catastrophe, the telephone men and women, unmindful of hardship, carried on with resourcefulness and courage, and the result was an almost impossible job splendidly done.

Research in the field of radio telephone transmission has been specially pushed in the direction of increasing the efficiency and the steadiness of trans-oceanic circuits in anticipation of the adverse conditions likely to occur in 1940 and 1941 at the time of the expected maximum effect of sunspot disturbance. Highly efficient adjustable directional antennæ have been prepared. One of these, two miles long, is now being installed in the trans-Atlantic route. Two noteworthy achievements in civil and military aeronautics were made last year. One was the development of an accurate instantaneous terrain clearance indicator by which a pilot is at all times apprised of his height above the ground. The other was the development of an aeroplane locator for use at ground stations. By dialling the frequency of the aeroplane radio, the airport operator can see on a map the direction of any aeroplane within range. This should be of great value in reducing risks to aeroplanes in bad weather.

The Company has a memorial fund which provides annual awards in recognition of unusual acts of service. This year one (posthumous) gold medal with $£ 100$ and thirty-two bronze medals were awarded to individuals, and four special bronze plaques were awarded to groups of employees in recognition of their skill, courage and devotion to duty along the Ohio River Valley during the flood of January 1937. 